\title{
Netnography: Observing and Interacting with Celebrity in the Digital World
}

\author{
Ashleigh Logan, University of Strathclyde, Glasgow \\ Email: Ashleigh.logan@strath.ac.uk
}

Netnography is an interpretive, qualitative research method that was introduced to consumer research by Robert Kozinets (1998). Netnography adapts social science ethnographic research techniques such as non-participative and participative observation, photographs, unstructured and structured interviews etc. to explore the activities of cultures and communities that materialise in the online world through computer-mediated systems of information exchange (Kozinets, 2002). In my research, I have used participative netnography to explore the online self-presentation strategies of female fashion bloggers on social media platforms such as Facebook and Twitter. These women form a core part of the online Kate Middleton community and are ordinary individuals who employ 'microcelebrity' strategies to establish and maintain a loyal group of online followers (Marwick and Boyd, 2011). Kate Middleton, Her Royal Highness Catherine Duchess of Cambridge, is the wife of Prince William and the mother of Prince George of the United Kingdom. Kate has an unprecedented effect on the British economy as the fashion brands she wears instantaneously sell-out online. By outlining Kozinets' $(2002,2009)$ guidelines and drawing on my own experiences of using netnography, I will demonstrate how social media content can be collected and analysed to provide a deep understanding of the cultural logic of celebrity.

\section{Entering the Field}

Today, online conversations often take place across several communicative platforms and involve multiple community members. This means that the field and its boundaries are best defined by a "set of practices and activities carried out over multiple online platforms" (Kulavuz-Onal and Vásquez, 2013, p. 228). This was the case in my study. Entering the field began when I started to observe the way in which four prominent female fashion bloggers in the Kate community presented the self online and the ways in which they frequently interacted with their 1000+ followers on and across their Facebook groups and Twitter profiles. These women were actively engaged in the practice of 'replikating' (buying the 
same brands and items of clothing as Kate) and/or 'copykating' (buying more affordable brands and items that are in the same style as those worn by Kate). From February 2014 to October 2014 I observed, interacted and engaged with these bloggers and their followers as a participant observer. Observations, interactions and reflections were recorded in field notes. Data was captured, visually via screen-shots and the copy and paste method.

\section{Types of data and analysis procedures}

In a netnographic study, there are no restrictions about what type of online information can be used as data (Kozinets, 2002, 2009). The amount and type of data collected varies and is largely dependent on the nature of the phenomenon of interest. Once data saturation is reached i.e. when no new ideas or themes emerge, this is usually a good indication that enough data has been collected. The social media element of my netnographic study lasted nine months. It contained 831 Facebook posts and 431 Tweets and included both pictorial and textual data. This data was analysed in the same way as traditional ethnographic data. Open and axial coding procedures were followed to identify themes in the data. In the open-coding stage, words and sentences loaded with meaning were identified in the text and key aspects of image composition (figure, background, body language, fashion, colours, likeness to Kate) which were believed to help address the research question were highlighted and then re-analysed to find patterns of meanings and core themes.

My data included participant self-made photo collages which were shared on Facebook groups and Twitter accounts. These often included a photograph of Kate in a particular outfit with text explaining what the item of clothing is called, the brands and how much it costs (e.g. Kate Reiss Shola dress £140). They also include a photograph of the participant alongside this photograph of Kate wearing the exact same items of clothing and a breakdown of their source and expenditure (e.g. sale price $£ 120$ on eBay). These photo collages were used by participants to not only explain the 'how to' or the instruction of 'replikating' but also to boost their popularity as 'micro-celebrities' who 'piggyback' off of Kate Middleton's recognisability as a fashion icon. Facebook posts themselves were also a core source of data. For example, some participants created status updates which offered incentives for their followers to post more frequently in the group. One participant provided an incentive in the form of a self-made tote bag complete with an iconic silhouette of Kate Middleton wearing her tiara. This was awarded to the five lucky followers who received the highest number of likes, comments and shares of their 'replikate' or 'copykate' outfit 
photograph post. Twitter was used in a similar way. The bloggers composed short bursts of information about the quality of 'replikate' and 'copykate' items and where and how to buy particular brands and items of apparel. They also used images of themselves dressed like Kate to gain recognition from their followers as experts at achieving the desired, optimal replikate look.

\section{Rules of Thumb}

Kozinets (2009) highlights four important differences between face-to-face social interactions and online social interactions: alteration, anonymity, accessibility and archiving. Alteration is essentially the familiarisation with the codes and norms of online behaviour. For example, in the online Kate community it was important to understand the ways in which different bloggers alternated between the terms 'replikate' and 'copykate'. This was important for understanding the hierarchy of these bloggers within the community, as the power of 'micro-celebrity' was higher for those who 'replikate'.

Next, care must be taken to preserve the anonymity of the research participants. This is because preserving an individual's right to use pseudonyms can help them to better express their creativity, identity and opinions in an more open unrestricted way. The ability to preserve anonymity can conflict with the next point 'accessibility'. This is because the wide availability, accessibility, and public and private nature of social media platforms means that attention seeking behaviour and voyeurism are common characteristics of those who present the self online. Certainly, in my study, the bloggers wanted their identity and presence to be known. They were 'piggybacking off of' Kate Middleton's world renowned public status as a female fashion icon and sought recognition from their followers for being the best at 'replikating' or 'copykating' Kate's style. Lastly, digital communications can be archived and conversation threads can take place over a number of years. The approach to making online social media based observational field notes is not the same as in ethnographic studies. On the one hand social media platforms provide a rich archive of celebrity data that can be revisited and analysed repeatedly in the manner in which it occurred in real-time. On the other, this data can be ephemeral which means that it can be momentarily uploaded and then deleted either by the individual or by platform owners. This means that pieces of the puzzle can be absent which is why it is better to conduct a netnographic study in real-time.

\section{Netnography and Celebrity Studies}


Netnography can be used to overcome some of the methodological challenges that celebrity scholars face because it enables the researcher to capture information produced by not only micro-celebrities but also other types of celebrity and high profile individuals. This information is publicly available on social media platforms. Obtaining data in this way alleviates difficulties associated with attaining celebrity consent prior to data collection, which include: access, tracking interactions amongst communities; level of influence; and identifying strategies of self-promotion.

There is dispute amongst those who use netnography as to whether passively observing is enough to provide a real understanding of the activities, beliefs and practices of an online culture or community (Kozinets, 2009). Said critique stems from the need to 'go native' by participating as a member of the online culture or community that, as a researcher, you seek to explore and understand. In this instance, using netnography to understand a particular celebrity may necessitate that the researcher engages in prior groundwork such as: frequently following a celebrity and responding to their posts and tweets; sharing and retweeting the celebrity's updates; following others who are friends with the celebrity online etc. This groundwork is not only data itself but it also helps lay the foundations of the researcher-celebrity relationship. It can lead to richer data, such as interviews that take place on real-time chat rooms, instant messaging and real-time face-to-face communication platforms e.g. FaceTime and Skype. The down side is that richer data of this nature may require formal ethical consent and could be more difficult to ascertain.

I hope my piece has suggested both how the cultural logic of celebrity, and methods for analysing it, are changing with social media. By walking through my own experiences of using netnography in my study of the online Kate Middleton community, I introduce netnography as a possible method for celebrity researchers and demonstrate how Facebook posts and Tweets can be used as insightful qualitative research data. 


\section{References}

Kozinets, R.V., 1998. On netnography. Initial reflections on consumer investigations of cyberculture. Advances in Consumer Research, Association for Consumer Research, Provo, UT, 25, 366-71.

Kozinets, R. V., 2002. The field behind the screen: Using netnography for marketing research in online communities. Journal of Marketing Research, 39 (1), 61-72.

Kozinets, R.V., 2009. Netnography: Doing ethnographic research online, Thousand Oaks, CA: SAGE Publications Ltd.

Kulavuz-Onal, D., \& Vásquez, C., 2013. Reconceptualising fieldwork in a netnography of an online community of English language teachers. Ethnography and Education, 8 (2), $224-238$.

Marwick, A., \& Boyd, D., 2011. To see and be seen: Celebrity practice on Twitter. Convergence: The International Journal of Research into New Media Technologies, 17 (2), 139-158. 
Bio

Ashleigh Logan is an ESRC (Economic Social Research Council) funded Ph.D. candidate in Marketing and Consumer Culture at the University of Strathclyde. Her recent work explores how consumers negotiate the feminine ideologies surrounding the Kate Middleton brand into sources of meaning for their identity projects.

\section{Contact Details}

Ashleigh Logan

University of Strathclyde

Department of Marketing

Sir William Duncan Building

130 Rottenrow

Glasgow

G4 0GE

Ashleigh.logan@strath.ac.uk 